\section{Tobacco control is losing ground in the Web 2.0 era: invited commentary}

Freeman's article ${ }^{1}$ on new media describes a number of vexing challenges and exciting opportunities for tobacco control. In the offline world, we have many solid 'wins' for tobacco control where we have strong evidence of what policies and programmes work and we have successfully put them into practice. These strategies include increasing tobacco excise taxes, passing smoke-free air laws, implementing countermarketing campaigns and offering tobacco cessation assistance. ${ }^{2-5}$ By contrast, with Internet $2.0,{ }^{1}$ the field of tobacco control does not have a comprehensive list of effective policies and programmes to counteract the sale and promotion of tobacco products in the new media environment. We are distressed to see that with the progression of new technology, the gap between 'pro-tobacco' and tobacco control forces seems to be growing larger. This should be a wakeup call for a more concerted effort.

For example, in the offline world, one of our greatest concerns is aggressive price discounting, which leads to cheaper cigarettes that undermine quit attempts and undercut the impact of price increases. ${ }^{6-8}$ A store might offer a carton of cigarettes at a $\$ 10$ discount. However, internet cigarette vendors offer the ultimate price discount, with prices for Marlboro Red at US\$22.00 compared with $\$ 80$ to $\$ 100$ in higher tax jurisdictions. ${ }^{9}$ There is some evidence that credit card and shipping bans in the USA have led to a reduction in traffic to internet cigarette vendors, ${ }^{10}$ but few studies have evaluated strategies to curtail duty free and discounted tobacco sales occurring online.

The use of social media to promote tobacco products is another cause for concern. As Freeman noted, ${ }^{1}$ abundant protobacco content has been featured on YouTube. In a 2010 study, Freeman and Chapman found that employees of British American Tobacco (BAT) actively promoted the company and its brands through Facebook. Their research uncovered over 430 Facebook pages and groups promoting two of BAT's global cigarette brands and about 60 Facebook groups promoting the BAT company itself. ${ }^{11}$ YouTube and Facebook represent only a fraction of social media in use. From Google+ to Tumblr, Twitter to StumbleUpon, the list of social media is long and rapidly expanding, and it is unclear to what extent these channels are being leveraged to promote pro-tobacco content.

The anonymity of the internet makes it a very difficult medium to regulate, and Freeman ${ }^{1}$ acknowledges that a major challenge to the enforcement of tobacco advertising bans is the inability to distinguish pro-tobacco content authored by tobacco companies or their affiliates from content authored by citizens. However, as pointed out in an earlier review, ${ }^{12}$ we would emphasise that regardless of who creates online content promoting tobacco use, the impact is likely to be the same; pro-tobacco content normalises tobacco use, encourages initiation and thwarts cessation attempts. Therefore, regulation of pro-tobacco internet content needs to be a priority - not an option. The guidelines for implementing Article 13 of the WHO Framework Convention on Tobacco Control provide a starting point for Internet regulation. For example, they highlight social networking sites as an example of a 'content host' and note that they 'should have an obligation to remove or disable access to tobacco advertising, promotion and sponsorship once they have been made aware of the content'. They also ask parties to require the tobacco industry to disclose information about their advertising activities and provide guidance on how parties might collaborate to address cross-border advertising issues. ${ }^{13} 14$
In addition to government regulation and enforcement, we propose the following strategies for redoubling tobacco control efforts in the Web 2.0 era:

1. Gaining a thorough understanding of the social media landscape and developing methods to monitor social media's treatment of pro-tobacco content should be a priority. There is a need for better surveillance of pro-tobacco content (sales websites, advertisements, brand websites, new media), and knowledge about the impact of consumer exposure to this content is lacking. Given the large amount of time people spend online with social media, it is surprising that the literature in this area is so sparse

2. There should be a firewall blocking underage youth from purchasing tobacco products online and being exposed to branded advertising and promotion of tobacco products. In addition to age verification, we need better identity verification so that online purchasers cannot buy anonymously and, as a result, tax evasion can be prevented and the sale of cheap tobacco products can be curbed.

3. Methods are needed to detect and prevent exposure to online tobacco company brand promotions in real time.

4. We must develop countermarketing 2.0 campaigns that include bold, aggressive interventions and digital content. There are endless examples of effective offline media campaigns but few examples of successful digital campaigns. Most of the existing evidence for online tobacco control focuses on tobacco cessation, which, while undoubtedly important, is only one part of the tobacco control picture. More research is needed to understand how best to use digital campaigns for the purpose of prevention. What kinds of messages might be most salient with users of new media?

This list is certainly not exhaustive, rather it is intended to be a snapshot of suggested priorities as we strategise how to make up for lost ground in the Web 2.0 era. However, what is clear is that we cannot afford to neglect the online space any longer.

\section{Kurt M Ribisl, ${ }^{1,2}$ Catherine Jo ${ }^{1}$}

${ }^{1}$ Department of Health Behavior and Health Education, Gillings School of Global Public Health, University of North Carolina, Chapel Hill, North Carolina, USA; ${ }^{2}$ Lineberger Comprehensive Cancer Center, University of North Carolina, Chapel Hill, North Carolina, USA

Correspondence to Dr Kurt M Ribisl, Associate Professor, Department of Health Behavior and Health Education, UNC Gillings School of Global Public Health, CB \#7440, Chapel Hill, NC 27599, USA:

kurt_ribisl@unc.edu

\section{Competing interests None.}

Provenance and peer review Commissioned; externally peer reviewed.

Tobacco Control 2012;21:145-146. doi:10.1136/tobaccocontrol-2011-050360

\section{REFERENCES}

1. Freeman B. New media and tobacco control. Tob Control 2012;21:139-44.

2. World Health Organization. WHO Report on the Global Tobacco Epidemic, 2011 Warning About the Dangers of Tobacco. Geneva, Switzerland: WHO Press, World Health Organization, 2011.

3. World Health Organization. WHO Framework Convention on Tobacco Control. Geneva, Switzerland: WHO Press, World Health Organization, 2003.

4. U.S. Department of Health and Human Services. Reducing Tobacco Use: $A$ Report of the Surgeon General. Atlanta, GA: U.S. Department of Health and Human Services, Centers for Disease Control and Prevention, National Center for Chronic Disease Prevention and Health Promotion, Office on Smoking and Health, 2000.

5. Institute of Medicine. Ending the Tobacco Problem: A Blueprint for the Nation. Washington DC: National Academy Press, 2007.

6. Pierce JP, Gilmer TP, Lee $L$, et al. Tobacco industry price-subsidizing promotions may overcome the downward pressure of higher prices on initiation of regular smoking. Health Econ 2005;14:1061-71.

7. Feighery E, Rogers T, Ribisl KM. Tobacco Retail Price Manipulation Policy Strategy Summit Proceedings. Sacramento, CA: California Department of Public Health, California Tobacco Control Program, 2009. 
8. Hyland A, Higbee C, Li Q, et al. Access to low-taxed cigarettes deters smoking cessation attempts. Am J Public Health 2005;95:994-5.

9. Kaplan M. A Pack of Cigarettes in New York City Now Costs \$11. 2010. http://www. publicradio.org/columns/marketplace/business-news-briefs/2010/06/

a new_york_city_pack_of_cigare.html

10. Rïisi KMM, Williams RS, Gizilice Z, et al. Effectiveness of state and federal government agreements with major credit card and shipping companies to block illegal Internet cigarette sales. PLoS One 2011;6:e16745.

11. Freeman B, Chapman S. British American tobacco on Facebook: undermining article 13 of the global World Health Organization Framework Convention on tobacco control. Tob Control 2010;19:e1-9.
12. RibisI KM. The potential of the internet as a medium to encourage and discourage youth tobacco use. Tob Control 2003;12(Suppl 1): i48-59.

13. Conference of the Parties to the WHO Framework Convention on Tobacco Control (FCTC). FCTC/COP/3/DIV/3, in Third Session of the Conference of the Parties to the WHO FCTC; 17-22 Nov 2008. Durban, South Africa, 2008. http://apps.who.int/gb/fctc/PDF/cop3/FCTC_COP3 DIV3-en.pdf

14. Allen M, Fieldsend A, Ribisl KM. Options for Future Action to Control Cross-border Tobacco Advertising, Promotion and Sponsorship. Wellington, New Zealand: Allen \& Clarke Policy and Regulatory Specialists, 2006. 